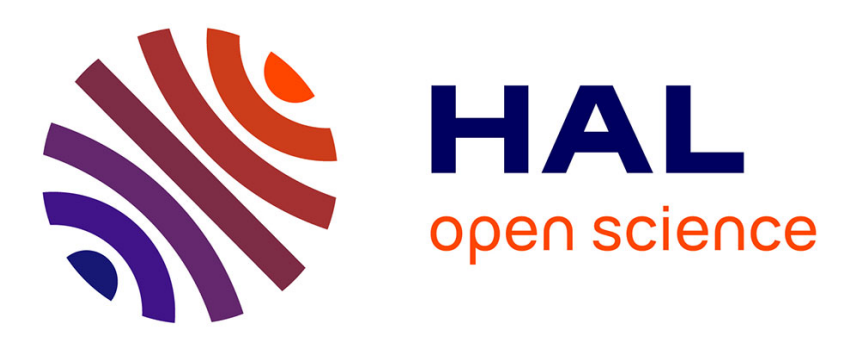

\title{
X-ray mono-Laue investigations of KAlF4 and RbAlF4: analysis of the displacive and martensitic transformations
}

\author{
Alain Gibaud, Alain Bulou, C. Launay, J. Nouet
}

\section{- To cite this version:}

Alain Gibaud, Alain Bulou, C. Launay, J. Nouet. X-ray mono-Laue investigations of KAlF4 and RbAlF4: analysis of the displacive and martensitic transformations. Journal de Physique, 1987, 48 (4), pp.625-633. 10.1051/jphys:01987004804062500 . jpa-00210478

\section{HAL Id: jpa-00210478 https://hal.science/jpa-00210478}

Submitted on 1 Jan 1987

HAL is a multi-disciplinary open access archive for the deposit and dissemination of scientific research documents, whether they are published or not. The documents may come from teaching and research institutions in France or abroad, or from public or private research centers.
L'archive ouverte pluridisciplinaire HAL, est destinée au dépôt et à la diffusion de documents scientifiques de niveau recherche, publiés ou non, émanant des établissements d'enseignement et de recherche français ou étrangers, des laboratoires publics ou privés. 
Classification

Physics Abstracts

$61.10-64.70 \mathrm{~K}$

\title{
X-ray mono-Laue investigations of $\mathrm{KAlF}_{4}$ and $\mathrm{RbAlF}_{4}$ : analysis of the displacive and martensitic transformations
}

\author{
A. Gibaud, A. Bulou, C. Launay and J. Nouet \\ Université du Maine, Laboratoire de Physique de l'Etat Condensé, U.A. n 807, C.N.R.S., \\ 72017 Le Mans Cedex, France
}

(Reçu le 11 juillet 1986, révisé le 10 novembre, accepté le 26 novembre 1986)

\begin{abstract}
Résumé. - L'étude comparative des différentes phases de $\mathrm{RbAlF}_{4}$ et $\mathrm{KAlF}_{4}$ est effectuée par la technique de "Laue monochromatique ». Une intensité diffuse importante est mise en évidence dans ces deux matériaux. Dans le cas de $\mathrm{RbAlF}_{4}$ qui présente des transitions de phase de nature displacive, la diffusion diffuse située au voisinage des pics de Bragg apparaissant après transition est bien interprétée à l'aide du spectre de phonons. Pour $\mathrm{KAlF}_{4}$ qui est le siège d'une transition «martensitique », la diffusion diffuse est localisée suivant des lignes et des taches supplémentaires sont observées. L'étude de l'arrangement des domaines à l'issue de la transition martensitique est effectuée.
\end{abstract}

\begin{abstract}
The technique of "monochromatic Laue " X-ray scattering has been used to carry out a comparative study of the different phases of $\mathrm{RbAlF}_{4}$ and $\mathrm{KAlF}_{4}$. In both materials diffuse scattering has been observed. In the former case where displacive transitions occur, the diffuse scattering is surrounding the superlattice Bragg peaks rising below $T_{\mathrm{c}}$ and is well interpreted in the light of the phonon spectrum. In the latter case where the transition is " martensitic ", the diffuse scattering is located along diffuse rods and several extra-spots have been observed. The domain arrangement following the martensitic transformation is studied.
\end{abstract}

\section{Introduction.}

$\mathrm{RbAlF}_{4}$ and $\mathrm{KAlF}_{4}$ crystals belong to the family of tetrafluoroaluminate layered compounds $\mathrm{MAlF}_{4}$ $\left(\mathrm{M}=\mathrm{Tl}, \mathrm{K}, \mathrm{Rb}, \mathrm{NH}_{4}\right)$ which were first investigated by Brosset [1] and later on by Fourquet et al. [2] and Bulou et al. [3, 4].

In these materials, the ideal structure (denoted phase I) encountered in the high temperature phases of $\mathrm{RbAlF}_{4}$ and $\mathrm{TlAlF}_{4}$ is characterized by infinite $\mathrm{AlF}_{6}$ octahedron sheets separated by the $\mathrm{Rb}^{+}$or $\mathrm{Tl}^{+}$ions. As shown in figure 1, in this ideal structure which corresponds to the tetragonal space group $\left(D_{4 h}^{1} P 4 / m m m Z=1\right)$, the octahedra are connected only by four fluorines denoted equatorial fluorines whereas the other two, denoted axial fluorines, are unshared and complete the octahedron. It is at this point that the structural difference between the tetrafluoroaluminates and the perovskites arises.

In the vicinity of $T_{\mathrm{c}_{1}}=553 \mathrm{~K}[3,4], \mathrm{RbAlF}_{4}$ undergoes a first structural phase transition (« weakly » first order) due to correlated rotations of $\mathrm{AlF}_{6}$ octahedra around the tetragonal $c$ axis. The space group becomes $D_{4 h}^{5}-P 4 / m b m-Z=2$ and is identical to that of $\mathrm{KAlF}_{4}[2,5]$ so that both crystals

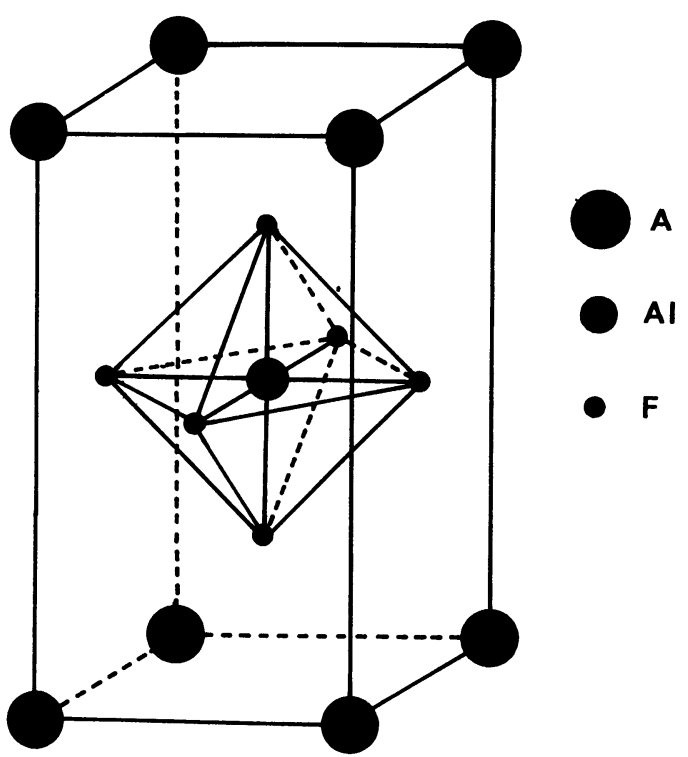

Fig. 1. - Ideal structure of the tetrafluoroaluminates $\mathrm{MAlF}_{4}(\mathrm{~A}=\mathrm{Rb}, \mathrm{Tl})$.

have at room temperature the same structure denoted phase II (let us note that $\mathrm{KAlF}_{4}$ does not exist in the ideal phase, the transition would occur above 
the melting point [6]). However although the structures of these two isomorphous compounds are the same at room temperature, they behave differently with the lowering of the temperature: whilst $\mathrm{RbAlF}_{4}$ undergoes a second order phase transition at $T_{\mathrm{c}_{2}}=282 \mathrm{~K}[3,4]$ (mainly due to octahedron tilts), $\mathrm{KAlF}_{4}$ undergoes at $T_{\mathrm{c}}=260 \mathrm{~K}$ a first order transition [7] which presents all the characteristic features of a martensitic transformation. In this case, the fact that the crystal breaks non reversingly at $T_{\mathrm{c}}$ makes the structural studies difficult in the low temperature phase denoted phase III. Moreover, it must be noted that the reverse transition phase III $\rightarrow$ phase II - presents a large hysteresis of about $100^{\circ} \mathrm{C}$ so that phase III can be studied at room temperature.

The structural results obtained by neutron powder diffraction pattern investigations recently performed in each material [3-8] are summarized in table I .

In $\mathrm{RbAlF}_{4}$ both transitions have been shown to be displacive : they arise from the condensation of soft modes at the $\mathrm{M}\left(T_{\mathrm{c}_{1}}\right)$ and $\mathrm{X}\left(T_{\mathrm{c}_{2}}\right)$ points of the ideal tetragonal Brillouin zone presented in figure 2 . In spite of the fact that $\mathrm{RbAlF}_{4}$ and $\mathrm{KAlF}_{4}$ structures are now well established, the reason for which these two compounds undergo a different SPT is not yet fully understood. In this context, we wish to present a comparative study of $\mathrm{KAlF}_{4}$ and $\mathrm{RbAlF}_{4}$ different phases carried out by the so-called "mono-Laue " technique. The purpose of the experiments was to find out whether the mono-Laue technique could provide additional information to the structural

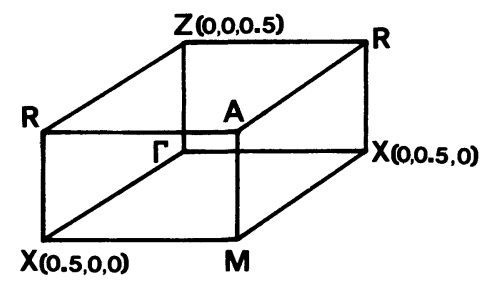

Fig. 2. - First Brillouin zone of the tetrafluoroaluminates in the ideal phase I (one eighth of the zone). studies already performed and how these informations could be connected to the nature of the different transitions occurring in the two compounds.

\section{Experimental.}

Single crystals of $\mathrm{RbAlF}_{4}$ and $\mathrm{KAlF}_{4}$ were prepared by the $I$ ridgman Stockbarger technique in our laboratory. In the case of $\mathrm{KAlF}_{4}$ two crystals were used to carry out the diffuse scattering measurements. The first one, denoted crystal $\mathrm{A}$, was directly grown from large amounts of pure $\mathrm{Al}_{2} \mathrm{O}_{3}$ and $\mathrm{KF}$ in a flux of $\mathrm{NH}_{4} \mathrm{HF}_{2}$ whereas the other one, denoted crystal $\mathrm{B}$, was grown from $\left(\mathrm{AlF}_{3}+\mathrm{KF}\right)$. In the latter case $\mathrm{AlF}_{3}$ was prepared by direct fluorination of $\mathrm{AlCl}_{3}$ (solid-gas reaction $\mathrm{AlCl}_{3}+\mathrm{HF}$ ) prior to the crystal growth and we have noticed that the quality of crystal B was not as good as that of crystal A.

Owing to the two-dimensional character of these compounds, cleavage is very easy in the plane perpendicular to the tetragonal $c$ axis. Samples can then be obtained in large platelets with a $c$ axis normal to their faces. On the contrary, samples containing the $c$ axis parallel to the crystal faces are always damaged during the cutting procedure and are subsequently of poor quality. For this reason and because the X-ray experiments performed in transmission necessitate thin samples (thickness typically less than $200 \mu \mathrm{m}$ ) we shall restrict this study to samples with the $c$ axis perpendicular to the crystal platelet face.

In all the experiments, crystals were stuck on a fiber and mounted with the $c$ axis parallel to the incident beam on a goniometer head.

The X-ray beam coming from a fine focus copper target was reflected on the (002) plane of a single bent pyrolytic graphite monochromator to collimate the $\mathrm{Cu} \mathrm{K \alpha}$ radiation and to focus in the vertical direction on a flat film. Owing to the $\mathrm{Rb}$ fluorescence with $\mathrm{Mo} \mathrm{K} \alpha$, the $\mathrm{Cu} \mathrm{K} \alpha$ radiation has been used in this study. The delimitation of the $\mathrm{X}$-ray beam size was achieved with tantalum slits placed between the monochromator and the sample. The diffuse scat-

Table I. - Space groups and lattice parameters (in $\AA$ ) of $\mathrm{RbAlF}_{4}$ and $\mathrm{KAlF}_{4}$ in their different phases. Glazer's notation (modified by Bulou [4]) indicates in which way the octahedra are rotated with respect to the ideal structure presented in figure 1.

\begin{tabular}{|c|c|c|c|}
\hline & Phase I & Phase II & Phase III \\
\hline $\mathrm{RbAlF}_{4}$ & $\begin{array}{c}\mathrm{D}_{4 \mathrm{~h}}^{1} \quad \mathrm{P} 4 / \mathrm{mmm} \quad Z=1 \\
a=3.6586(1) \quad c=6.3061(1) \\
\text { at } T=623 \mathrm{~K}(\operatorname{Ref} .[4]) \\
a^{0} \quad a^{0} \quad c^{0}\end{array}$ & $\begin{array}{c}\mathrm{D}_{4 \mathrm{~h}}^{5} \quad \mathrm{P} 4 / \mathrm{mbm} \quad Z=2 \\
a=5.1227(1) \quad c=6.2815(2) \\
\text { at } T=293 \mathrm{~K}(\mathrm{Ref} .[4]) \\
a^{0} \quad a^{\mathrm{o}} \quad c^{+}\end{array}$ & $\begin{array}{c}\mathrm{D}_{2 \mathrm{~h}}^{13} \quad \text { Pmmn } Z=4 \\
a=7.2285(2) \quad b=7.2073(2) \quad c=6.2624(1) \\
\text { at } T=200 \mathrm{~K} \text { (Ref. [4]) } \\
a_{\mathrm{p}}^{+} \quad b_{\mathrm{p}}^{+} \quad c^{+}\end{array}$ \\
\hline $\mathrm{KAlF}_{4}$ & & $\begin{array}{c}\mathrm{D}_{4 \mathrm{~h}}^{5} \quad \mathrm{P} 4 / \mathrm{mbm} \quad Z=2 \\
a=5.0424(1) \quad C=6.1564(1) \\
\text { at } T=293 \mathrm{~K}(\operatorname{Ref}[8]) \\
a^{0} \quad a^{0} \quad c^{+}\end{array}$ & $\begin{array}{c}\mathrm{C}_{2 \mathrm{~h}}^{2} \quad \mathrm{P}_{1} / \mathrm{m} \quad Z=4 \\
a=7.3403(2) \quad b=7.2370(2) \quad c=6.4070(2) \\
\left.\beta=106.801^{\circ} \text { at } T=4 \mathrm{~K} \text { (Ref. }[7]\right) \\
\text { shear transformation }\end{array}$ \\
\hline
\end{tabular}


tering by air was minimized with a collimator guiding the X-ray beam close to the surface of the sample.

To perform the experiments below and above room temperature, the crystals were set in a cold (or hot) stream of nitrogen gas whose temperature was regulated with an accuracy of $\pm 2{ }^{\circ} \mathrm{C}$.

The diffraction diagrams have been collected on flat instead of cylindrical films in order to facilitate the set-up of the temperature device and because the diffraction patterns were more symmetrical and therefore easier to interpret. The generator was working at $(40 \mathrm{kV}, 30 \mathrm{~mA})$ and exposure times were typically 8 hours for these non-very absorbing materials. As a consequence all the diagrams were systematically contaminated by the $\lambda / 2$ radiation coming from the reflection on the « $(004)$ » plane of the pyrolytic graphite monochromator.

\section{Experimental results.}

All the measurements were exclusively performed with the $c$ axis of the crystals parallel to the X-ray beam.

3.1 MONO-Laue PATTERnS OF THE SUCCESSIVE PHASES OF $\mathrm{RbAlF}_{4}$. - The mono-Laue patterns of $\mathrm{RbAlF}_{4}$ in the different phases are shown in figure 3 together with the indexation diagrams in the corresponding lattice (spots which remain unindexed are due to $\lambda / 2$ contamination).

In phase I, the use of the long wavelength $\mathrm{Cu} \mathrm{K \alpha}$ radiation together with the small lattice parameters of $\mathrm{RbAlF}_{4}$ would have made the mono-Laue pattern not very crowded, had it not been the presence of diffuse scattering (DS) (Fig. 3a). As evidenced by the indexation diagram, the only Bragg spots which are close enough from the Ewald sphere are the 111 and the 202 (with their symmetry equivalent spots). As they are inside the Ewald sphere (see indexation diagram), a small misorientation is then compulsory to bring some of these spots, namely the 111, 202 and 022 spots, onto the Ewald sphere. In addition to these Bragg spots, let us mention two unessential features which are spoiling this pattern :

- some spots (arrowed on the pattern) come from the $\lambda / 2$ contamination;

- some diffraction circles and spots arise from powder diffraction imputed to the deterioration of the crystal surface under the effect of the high temperature gas stream.

It can be deduced from phase I indexation diagram that the DS is located around the high symmetry $M(3 / 2,1 / 2,1)$ and $X(3 / 2,0,1)$ points (and with a weaker intensity between the $R$ and $Z$ points) $\left.{ }^{1}\right)$.

( ${ }^{1}$ ) It must be noted that the $\lambda / 2$ contamination which exists at these points cannot be confused with the DS which is broad and essentially temperature dependent.
Around the $\mathrm{X}$ points, DS extends along the $[100]_{\mathrm{I}}$ or $[010]_{\mathrm{I}}$ directions towards the $\mathrm{M}$ points but does not reach this point. On the contrary, at the $M$ points, the DS is much more concentrated. If compared to the 211 or 121 Bragg spots of figure $3 \mathrm{~b}$, it can even be seen that these diffuse $M$ points are nearly resolution limited in the $l=1$ reciprocal plane. Henceforth, the presence of DS at these points can be attributed either to atomic displacements nearly tridimensionally correlated or to a diffuse rod crossing the $l=1$ reciprocal plane perpendicularly at the $M$ point. In a general case, it would have been hazardous to discuss more about the origin of this DS. Nevertheless, the dynamical properties of $\mathrm{RbAlF}_{4}$ have already been studied [6, 9] and it is now valuable to comment these results in the light of the phonon spectrum.

It has been shown that the transitions in $\mathrm{RbAlF}_{4}$ are displacive and can be related to the condensation of soft phonons : softening occurs at the $M$ point at $T_{\mathrm{c}_{1}}$ and at the $\mathrm{X}$ point at $T_{\mathrm{c}_{2}}$. Thus, we would like to evidence that the DS observed on this film can be imputed to the low frequency phonons surrounding the $\mathrm{M}$ and $\mathrm{X}$ points.

Lut us first consider the DS anisotropy around the $X$ point. According to the indexation diagram, it can be seen that the points located along the MX line always nearly satisfy the diffraction condition. If we assume that DS is imputed to soft phonons, then the DS intensity at a $q$ position along the line is proportional to the inverse of the square frequency $\omega^{2}(j, q)$ of the phonon $j$ at this position and hence is closely related to the dispersion.

From the diffraction pattern, we can deduce that the dispersion is weak around the $\mathrm{X}$ point and that the DS roughly extends to half the length of the MX line. This is exactly what can be expected from the phonon dispersion curve $Y_{2}$ which shows that the phonon frequencies increase when the $\mathbf{M}$ point is approached (as shown in Fig. 4). Furthermore, from the DS extension we can infer that a typical « cutoff » frequency of about $1 \mathrm{THz}$ characterizes the experimental conditions provided that the background is coming from higher frequency phonons.

At the $M$ point, the DS is concentrated in a well defined spot. Figure 4 shows that the frequency of the $\mathbf{M}_{3}$ mode is very low and that the dispersion around this point is very steep ( $\mathrm{Y}_{3}$ phonon branch). The typical cut-off frequency is reached for a wavevector transfer $q$ (with respect to the $M$ point) less than 0.1 reciprocal lattice units. Let us note that the dispersion curve along the MA line is flat [9] ; this flatness should give rise to diffuse rods but the present geometry only allows us to observe the intersection point of these rods with the Ewald sphere. Moreover the fact that the small misorientation of the crystal increases and concentrates a bit the DS intensity around the upper $X$ points of the 

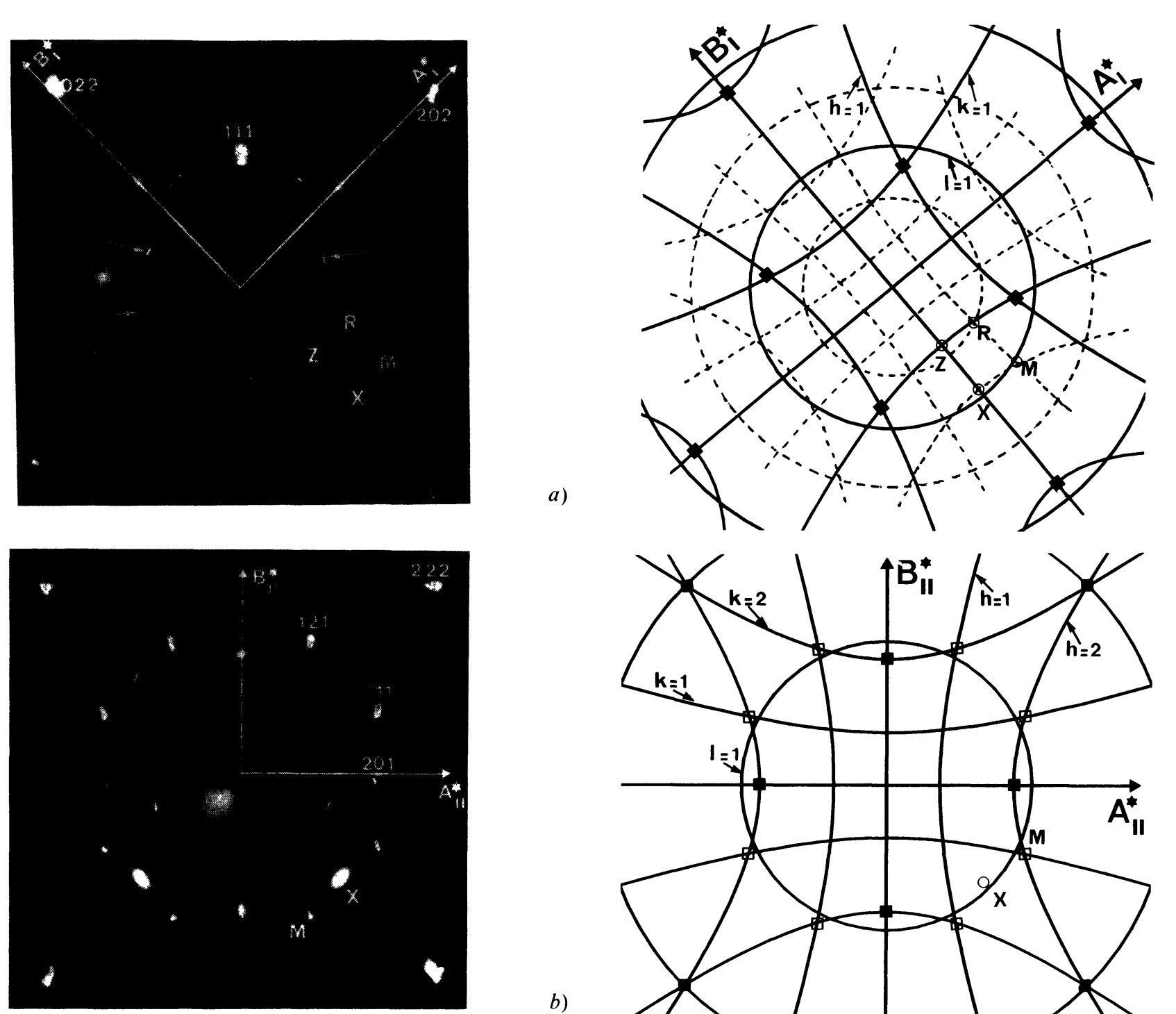

a)

b)
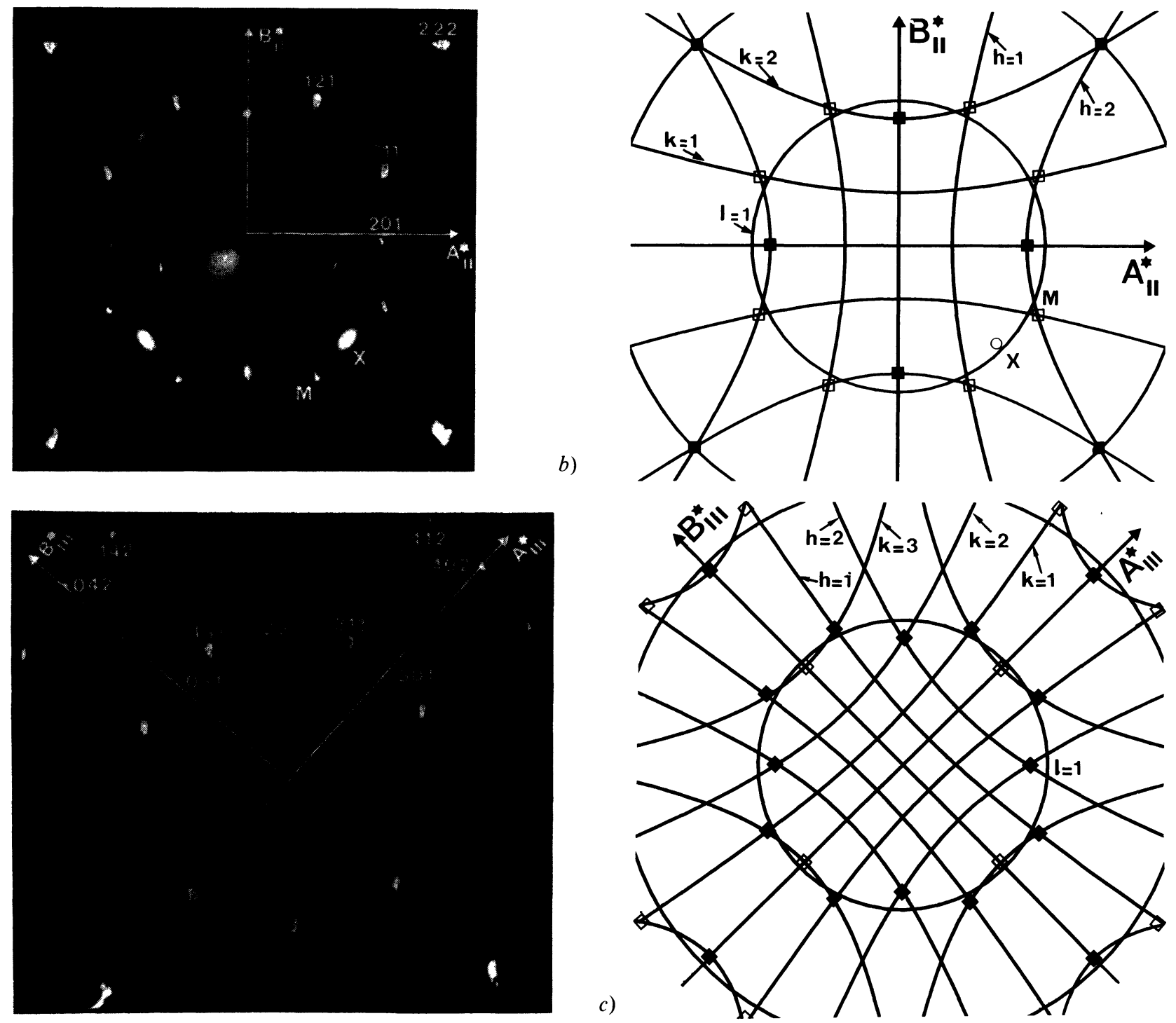

Fig. 3. - Indexation diagrams and typical mono-Laue patterns of $\mathrm{RbAlF}_{4}$ recorded on flat films with the $\mathrm{X}$-ray beam along the tetragonal $c$ axis : a) phase I at $T=620 \mathrm{~K}$. b) phase II at $T=290 \mathrm{~K}$. c) phase III at $T=240 \mathrm{~K}$. (In the indexation diagrams, open squares represent the new superlattice Bragg spots in each phase and full squares the Bragg spots. Dashed lines in figure $3 \mathrm{a}$ represent the $h / 2, k / 2, l / 2$ ( $h k l$ odd) lines. Arrowed spots are due to $\lambda / 2$ contamination.) 


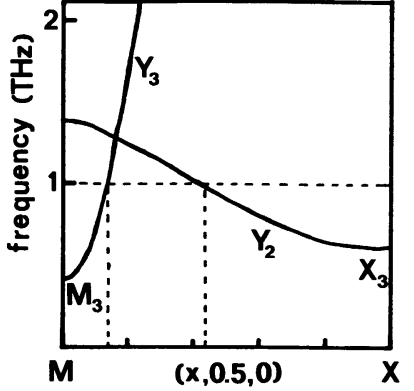

Fig. 4. - Part of the calculated phonon dispersion curves of $\mathrm{RbAlF}_{4}$ at $T=673 \mathrm{~K}$ between the $\mathrm{M}$ and $\mathrm{X}$ points. (After A. Bulou [6].)

pattern without affecting the DS at the $M$ point confirms the existence of the diffuse rods.

With the lowering of temperature below $T_{\mathrm{c}_{1}}=553 \mathrm{~K}$, the diffuse $(h+0.5, k+0.5,1) \mathrm{M}$ spots are transformed into superlattice Bragg spots as shown on pattern $3 \mathrm{~b}$ recorded at $300 \mathrm{~K}$. The superlattice Bragg peaks are characteristic of a new unit cell with lattice parameters :

$$
\begin{gathered}
\mathbf{a}_{I I}=\mathbf{a}_{\mathrm{I}}+\mathbf{b}_{\mathrm{I}} \\
\mathbf{b}_{\mathrm{II}}=-\mathbf{a}_{\mathrm{I}}+\mathbf{b}_{\mathrm{I}} \quad \mathbf{c}_{\mathrm{II}}=\mathbf{c}_{\mathrm{I}}
\end{gathered}
$$

in agreement with the $\mathrm{RbAlF}_{4}$ phase II structural studies $[3,4]$ which showed that, at $T_{\mathrm{c} 1}, \mathrm{AlF}_{6}$ octahedra rotate around the tetragonal $c_{\mathrm{I}}$ axis. It is then obvious that owing to the change of periodicity, superlattice Bragg spots must be expected at the $M$ points of the Brillouin zone. It can be noticed that in this case the intensity observed at the $M$ points is only due to the off-centre displacements of the equatorial fluorines.

This decrease of temperature also produces a change in the DS anisotropy located around the $\mathrm{X}$, $R$ and $Z$ points. Around the $R$ and $Z$ points, the $D S$ observed in phase $I$ disappears whereas on the contrary the DS persists around the $X$ point with an extension hardly narrower than in phase I. However, the intensity close to the $\mathrm{X}$ point grows as expected from the softening of the $\mathrm{X}_{3}$ phonon when $T_{\mathrm{c}_{2}}$ is approached. This indicates that the correlation length along the $[100]_{\mathrm{I}}$ or $[010]_{\mathrm{I}}$ directions increases and that the second phase transition is imminent at this temperature.

Indeed on pattern $3 \mathrm{c}$, recorded at $250 \mathrm{~K}$, the diffuse $\mathrm{X}$ points are now concentrated in the superlattice $(h+0.5, k, l)$ or $(h, k+0.5, l)$ Bragg spots (with respect to the Miller indices of phase I). The new unit cell is then characterized by the following lattice parameters :

$$
a_{I I I}=2 a_{I}, \quad b_{I I I}=2 b_{I}, \quad \text { and } \quad c_{I I I}=c_{I}
$$

in agreement with previous structural studies $[3,4]$. The change of periodicity and the concomitant new superlattice Bragg spots come from octahedron rotations around the $a_{\mathrm{I}}$ or $b_{\mathrm{I}}$ axes together with a translation of the $\mathrm{Rb}^{+}$ions along the $c$ axis [4].

Once again, it must be pointed out that a small misorientation is compulsory to bring the $\mathrm{X}$ points through the Ewald sphere. This was achieved by rotating the crystal counterclockwise around the horizontal axis of the pattern. Thus the $\overline{3} 01,0 \overline{3} 1$, $142, \overline{1} 42,412$ and $4 \overline{1} 2$ superlattice Bragg spots were brought in contact with the Ewald sphere. It can then be noticed that a large diffuse scattering is still superimposed $30 \mathrm{~K}$ below $T_{c_{2}}$ to narrow well defined $\overline{3} 01$ and $0 \overline{3} 1$ superlattice Bragg spots which have been brought right in contact with the Ewald sphere. This feature is consistent with the soft mode picture and shows that the soft phonon branch is still of low frequency at this temperature as shown by Raman scattering studies [10].

3.2 Diffuse SCATtERING AND PHASE TRANSITION IN $\mathrm{KAlF}_{4}$. - The monochromatic diffraction pattern of the room temperature phase of $\mathrm{KAlF}_{4}$ (crystal A) is presented in figure 5a. The analogy of the diffraction diagram with that of $\mathrm{RbAlF}_{4}$ in phase II is obvious and consistent with the fact that both compounds have the same average structure at room temperature. As expected the $\mathbf{M}$ points are alight and give evidence of the octahedron rotation around the $c$ axis. We note a very intense DS joining the 211 to the 121 Bragg peaks. In analogy with the analysis of the $\mathrm{RbAlF}_{4}$ phase II diffraction pattern, this result suggests that a flat branch of phonons extends from the $\mathrm{X}$ to the $\mathrm{M}$ point in $\mathrm{KAlF}_{4}$. Because the diffuse intensity vanishes when the crystal is tilted around the $b_{\mathrm{II}}$ axis (the angle of misorientation is not critical), it can be inferred that the DS is concentrated along rods parallel to the $[100]_{\mathrm{I}}$ and $[010]_{\mathrm{I}}$ directions. .This must be imputed to planar correlations of atomic displacements in planes perpendicular to that direction. Owing to the large extension of the diffuse scattering along the MX line, correlations between adjacent planes are nearly inexistent. No significant change in this diffraction pattern was observed when the temperature was lowered close to $T_{\mathrm{c}}$. In addition to the DS observed between the $\mathrm{M}$ and $X$ points, a weak diffuse intensity is also measured at the $\mathrm{Z}$ point (see indexation diagram Fig. 3).

In figure $5 \mathrm{~b}$, we present a mono-Laue pattern of crystal B. In this case it can be noted that, in addition to the characteristic features of crystal $A$ pattern, several extra-spots are located along the $\langle 110\rangle_{\text {II }}$ directions. Their intensities are very weak if compared to those of the Bragg peaks. The most intense spots are found to be around the 201 Bragg spot. With respect to the $\mathbf{a}_{\text {II }}, \mathbf{b}_{\text {II }}, \mathbf{c}_{\text {II }}$ system of axes, these spots are located at

$$
\mathbf{Q}=\mathbf{H}+\mathbf{q} \quad \text { with } \quad \mathbf{q}=+0.16(5) \mathbf{a}_{\mathrm{II}} \pm 0.16(5) \mathrm{b}_{\mathrm{II}}
$$



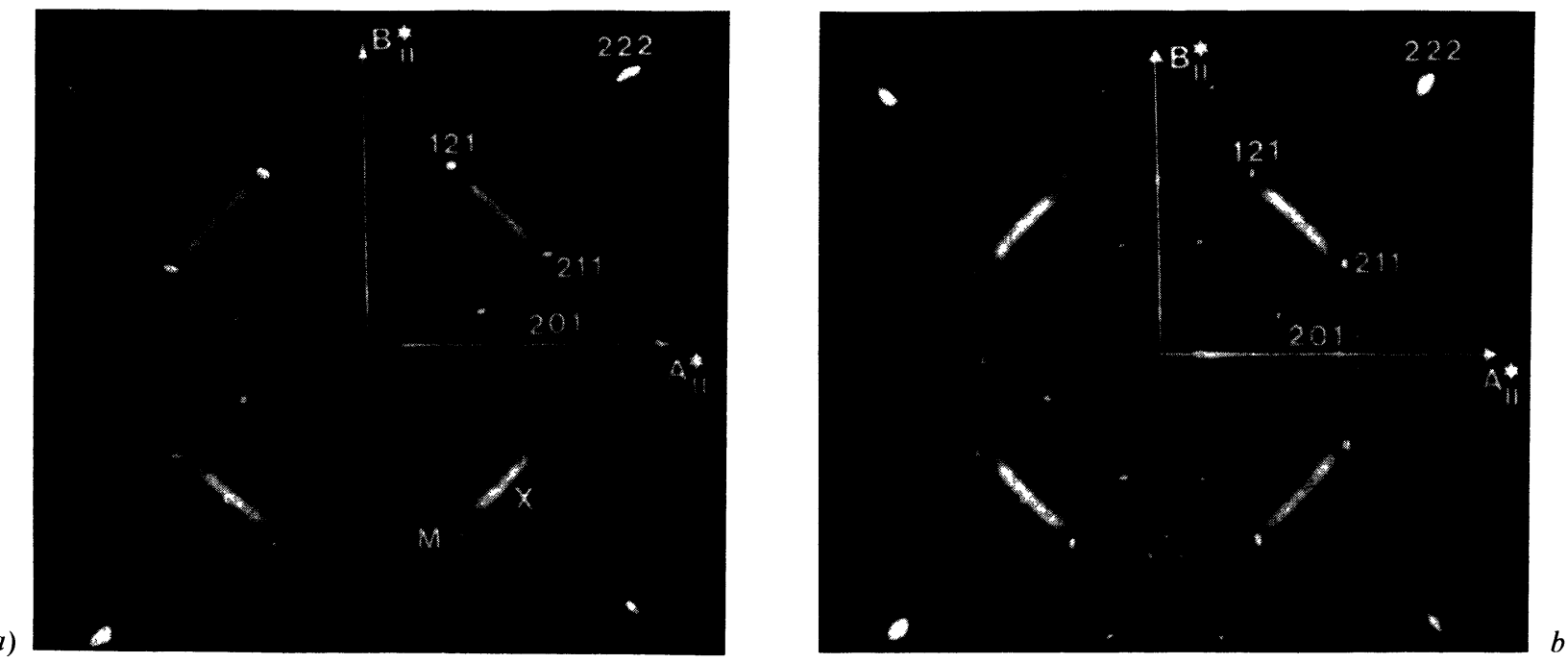

b)
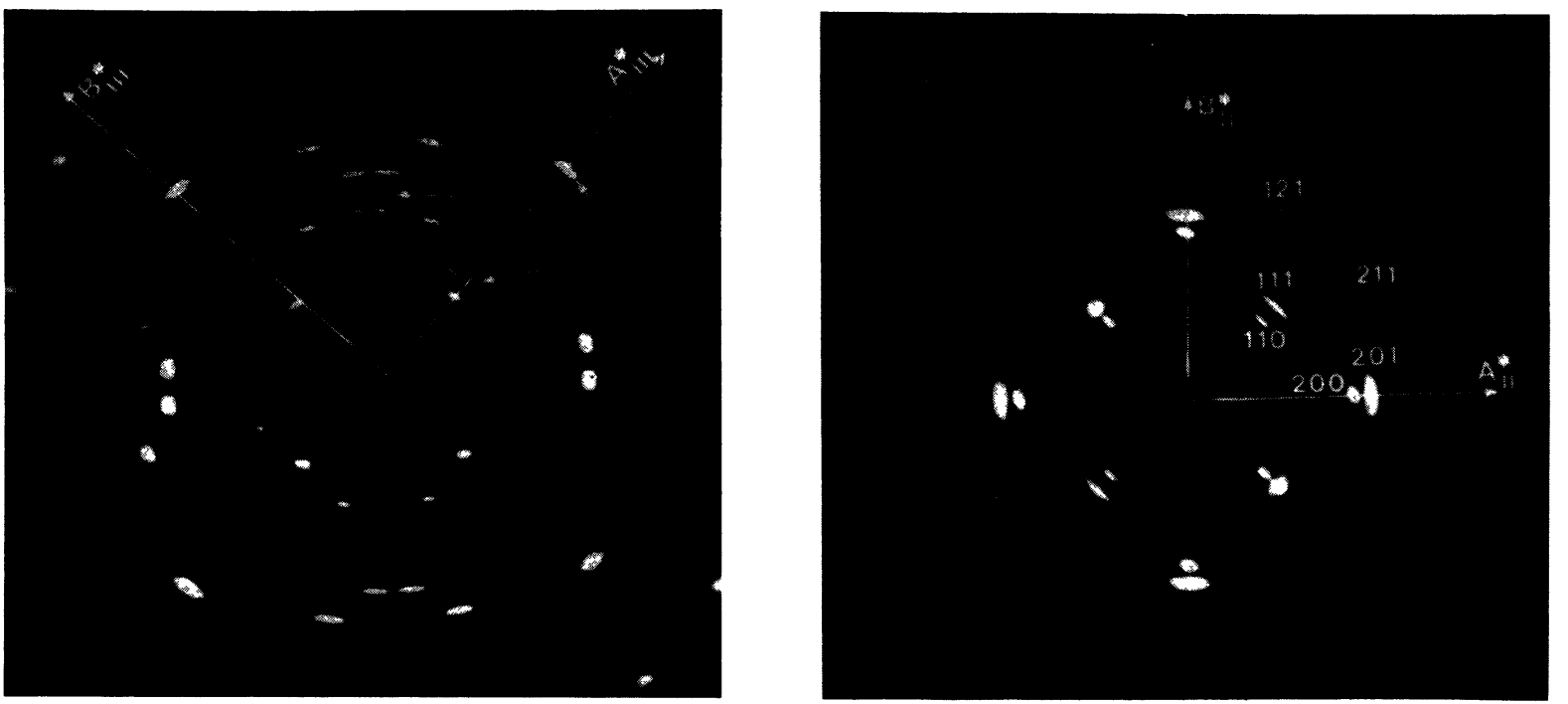

d)

Fig. 5. - Typical mono-Laue patterns of $\mathrm{KAlF}_{4}$ recorded on flat films with the tetragonal $c$ axis along the incident beam : a) crystal A at room temperature ; b) crystal B at room temperature ; c) phase III at $T=240 \mathrm{~K}$; spots in full arrows arise from the coexistence of a small amount of phase II with phase III ; d) phase II after warming up a crystal which had undergone the structural phase transition phase II $\rightarrow$ phase III. The crystal was heated at $100^{\circ} \mathrm{C}$ during about $2 \mathrm{~min}$ and the pattern was then recorded at room temperature.

$\mathbf{H}$ being the reciprocal lattice vector associated with the 201 Bragg spot. No similar extra spots have been observed in $\mathrm{RbAlF}_{4}$. It is also remarkable that the intensity of the extra-spots is almost temperature independent since they are still present at $200 \mathrm{~K}$ above $T_{\mathrm{c}}$.

The decrease of temperature produces a drastic change of behaviour between $\mathrm{RbAlF}_{4}$ and $\mathrm{KAlF}_{4}$. Figure 5c shows a typical mono-Laue of $\mathrm{KAlF}_{4}$ in phase III at $T=250 \mathrm{~K}$. At this temperature the crystal is broken and Bragg spots are no longer sharp and narrow. However, it is remarkable that in spite of the broken crystal, the Bragg spots are still dispatched in a very symmetrical way. Their number and their shape (arc of circles) suggest that the pattern cannot be interpreted in a simple way as shown in the next section of this paper.

It can yet be noted that extra-spots visible in figure $5 b$ are now the most intense Bragg spots of phase III. This result suggests that their presence in phase II might be related to the coexistence of a small amount of phase III with phase II, or that a correlated motion of atomic displacements having the same periodicity as in phase III can be observed in phase II. This is a rather surprising result in the light of the reconstructive mechanism which is involved at the phase II $\rightarrow$ phase III transition. However as the existence of extra-spots is sample related, it seems that extrinsic parameters could play a major role in their origin. In this plastic material, the 
cleavage procedure could also produce damages locally favourising the appearence of a small amount of phase III.

Note that similar premartensitic effects have already been observed in metallic alloys [11-13]. They were interpreted $[11,13]$ as coming from chargedensity-wave (CDW) formation and were associated with an anomalous feature in the TA phonon dispersion curve. In an alternative approach, Shapiro et al. [12] suggest that this anomaly could favour the presence of a metastable phase in such alloys and explain the premartensitic effects.

Because $\mathrm{KAlF}_{4}$, which cannot exhibit CDW, presents similarly to premartensitic phases extra-spots lying along the direction of a soft phonon branch, the knowledge of the domain arrangement following the martensitic transformation appears to be very informative to understand the premartensitic effects in this compound.

\section{The domain arrangement in phase III of $\mathrm{KAlF}_{4}$.}

\subsection{ASSUMPTIONS USED FOR THE SIMULATION OF} THE $\mathrm{KAIF}_{4}$ PHASE III DIFFRACTION PATTERN.

4.1.1 Unit cell. - In order to interpret the $\mathrm{KAlF}_{4}$ phase III mono-Laue pattern, we assumed that the structure at $250 \mathrm{~K}$ is the same as that determined at $T=4 \mathrm{~K}$ by neutron powder diffraction. As shown in [7], the structure is described by a monoclinic unit cell with the lattice parameters (at $4 \mathrm{~K}$ ) :

$$
\begin{gathered}
a_{\mathrm{m}}=7.340 \AA, \quad b_{\mathrm{m}}=7.237 \AA, \\
c_{\mathrm{m}}=6.407 \AA \quad \text { and } \beta=106.71^{\circ}
\end{gathered}
$$

with the $\mathrm{P} 21 / \mathrm{m}$ space group symmetry.

However the monoclinic distortion is very weak and the structure can be alternatively described with an orthorhombic face centred cell with the lattice parameters :

$a_{0}=3.670 \AA, \quad b_{0}=7.340 \AA$ and $c_{0}=12.313 \AA$

(in the corresponding $B$ face-centred monoclinic cell $\beta=90.18^{\circ}$ ).

Since in the X-ray powder diffraction patterns the reflections characteristic of the monoclinic symmetry are very weak and are too small to be observed, we have found it convenient to use in the following the simplest description i.e. the orthorhombic unit cell.

4.1.2 Domain arrangement. - A calculation of the diffraction diagram in the framework of the (pseudo) orthorhombic cell of phase III predicts a number of Bragg reflections much smaller than that observed in the experimental pattern. As a result, we have assumed that $\mathrm{KAlF}_{4}$ crystals ought to present in phase III several misorientated domains arranged in a non-random way to account for the symmetry present in the pattern. Although first evidenced by X-ray diffraction, the presence of macroscopic domains at the surface of the samples has been observed by conventional microscopy and by electron microscopy as recently reported in [7].

It can be noticed in figure $5 \mathrm{c}$ that :

- the apparent fourfold axis present in the pattern is not consistent with a monoclinic or an orthorhombic space group;

- in spite of the fact that the crystal was kept fixed during the exposure, most of the spots are located along the lines of constant indices $h$ or $k$. This makes the pattern reminiscent of a pattern presenting a « fiber axis».

To account for these two observations it can be assumed that :

- owing to the poor resolution of the instrument and to the weak difference between the values $2 a_{\text {III }}$ and $b_{\text {III }}$ of the lattice parameters, two orthogonal domains turned from $90^{\circ}$ around the $c$ axis could explain the presence of the pseudo fourfold axis;

- the $b_{\mathrm{III}}$ (or the $a_{\mathrm{III}}$ ) axis must be considered as a fiber axis to explain that even though the crystal is kept fixed during the exposure, the spots are located along the line of constant indice $k$ (or $h$ ).

Moreover, since two orthogonal domains are superimposed it is possible to explain the presence of the spots along both lines $h$ and $k$ constant with only one fiber axis such as for instance the $b_{\mathrm{III}}$ axis. This axis was chosen because the shear transformation which occurs at the transition implies the gliding of octahedron sheets along the $a_{\mathrm{III}}$ axis.

From these above considerations, the simulation was then carried out assuming the superposition of two orthogonal domains with a continuum of misorientation of up to $+30^{\circ}$ around the $b_{\mathrm{III}}$ axis considered as a fiber axis for both domains as shown in figure $6 a$.

\subsection{RESULTS AND COMMENTS ABOUT THE PATTERN} CALCULATION. - The results, presented in figure $6 \mathrm{~b}$, are on the whole in good agreement with the experimental pattern except that the two arrowed spots of figure 5c (and their fourfold axis equivalent spots) remain unindexed. A calculation performed in the monoclinic space group did not improve the agreement. On the other hand, the unindexed spots can be explained by assuming the coexistence of a small amount of phase II in phase III. This hypothesis is supported by the following reasons :

- the intensity of the unindexed spots decreased on cooling and increased on heating;

- when the hysteresis is over (i.e. $100{ }^{\circ} \mathrm{C}$ above $T_{\mathrm{c}}$ ), the very intense $111_{\mathrm{II}}$ and $201_{\mathrm{II}}$ Bragg spots are located at the position of the unindexed spots as shown in figure $5 \mathrm{~d}$.

Let us note in this figure that, although the crystal is now entirely back into phase II, the mono-Laue 


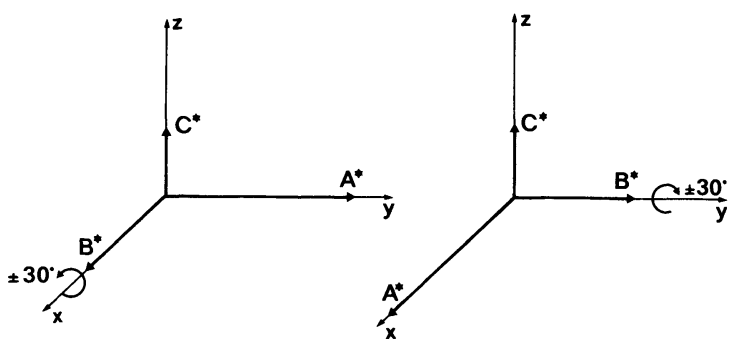

a)

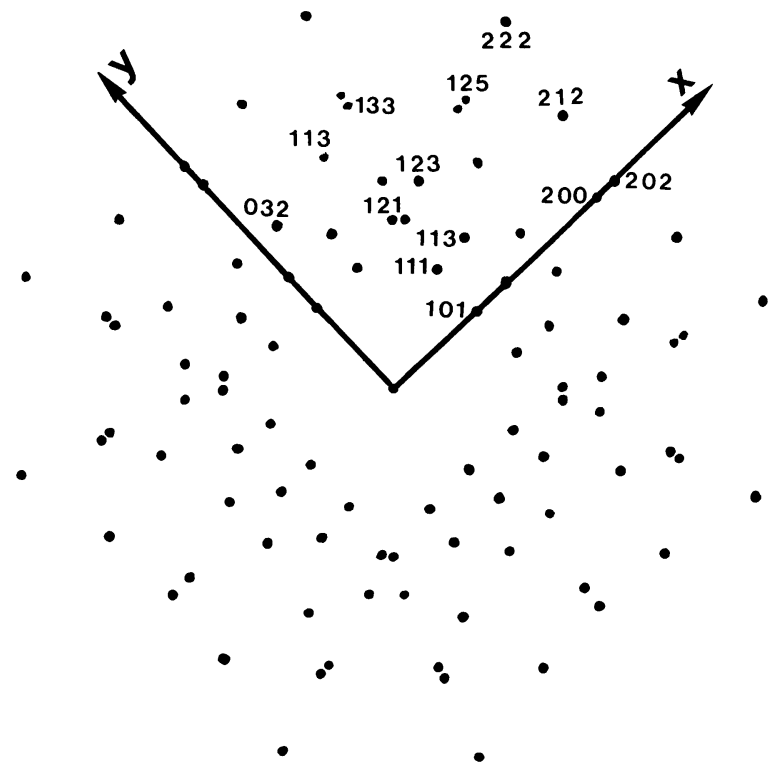

b)

Fig. 6. - a) Domain arrangement assumed to carry out the simulation of the $\mathrm{KAlF}_{4}$ diffraction pattern in phase III. In both domains the fibre axis was chosen to be the $b_{\text {III }}^{*}$ axis ; b) result of the simulation according to the above assumptions.

pattern looks completely different from what it was in phase II before the break (Fig. 5a). The diffuse scattering is no longer visible and it is necessary to invoke the same sort of misorientations as in phase III to index this pattern. To comment these results it must be added that :

- the above simulations have allowed us to index all the spots present in pattern of phase III ;

- it is very likely that this simulation is not fully suitable to describe the domain arrangement since it leads to dot-shaped spots and hence does not reproduce their real shapes.

A more realistic model must be considered to account for the information provided by the Buerger precession photograph $\left(^{2}\right)$ of the (100) reciprocal plane (with respect to the phase I axes) presented in figure 7 . In this pattern it is clear that the continuum

$\left(^{2}\right)$ This photograph was kindly provided by Prof. J. L. Fourquet.

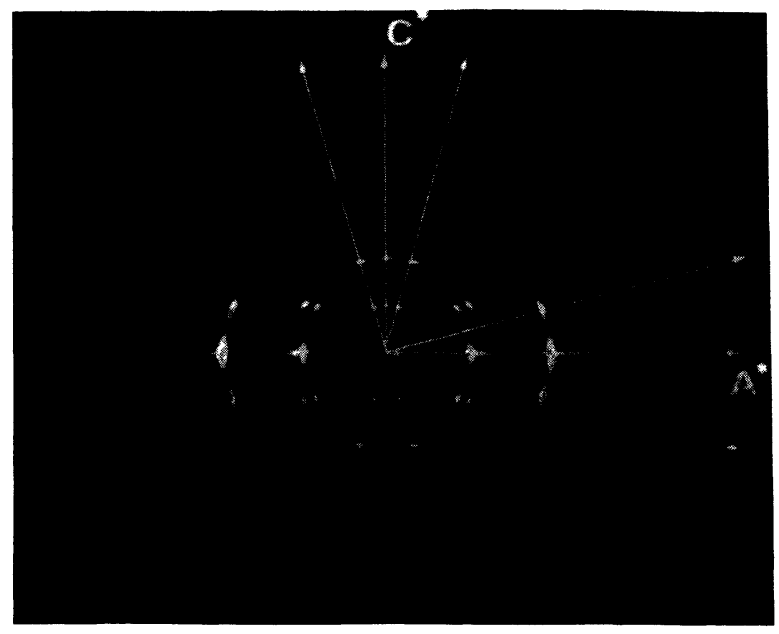

Fig. 7. - Buerger precession photograph of the (100) reciprocal plane (with respect to phase $\mathrm{I}$ cell) of $\mathrm{KAlF}_{4}$ in phase III (Mo $\mathrm{K} \alpha \mathrm{Zr}$ filtre) showing the presence of domains misorientated from about $+17^{\circ}, 0^{\circ}$ and $-17^{\circ}$ around the $b_{\text {III }}^{*}$ axis (Courtesy of J. L. Fourquet).

of misorientation around the $b_{\mathrm{III}}$ axis is not fully convenient and that it should be changed into a distribution of three misorientated domains. The $17^{\circ}$ angle of misorientation between the domains, observed in the Buerger photograph, is found to be consistent with the angle $\alpha=\beta-90^{\circ}=16.7^{\circ}$ which can be deduced from the structural rearrangement.

To explain the arc of circle-shaped spots we have considered $\mathrm{a} \pm 5^{\circ}$ scatter around the average position of each domain.

Moreover, since two orthogonal types of domains are superimposed, we have finally used a total number of six domains in the calculation. The simulation obtained explains the shape and all the spots belonging to phase III except the $200_{\text {III }}$ (dash-arrowed in the pattern) and its fourfold symmetry equivalent spots. In the previous hypothesis, this spot was misorientated from $25^{\circ}$ around the $b_{\text {III }}^{*}$ axis and it is clear that this angle cannot be reached in the latter assumption. It appears then that the situation could be intermediate between a continuum of misorientation and a discrete number of domains which are misorientated around their average positions. This statement is enhanced by the electron microscopy photographs [7] showing the presence of cracks at the sample surface of $\mathrm{KAlF}_{4}$ in phase III. At the crack positions, tiltings occurring simultaneously around the $a_{\mathrm{III}}$ and $b_{\mathrm{III}}$ axes are very likely. However, the fact that they mainly appear at the sample surface suggests that their contribution to the diffraction pattern is probably very weak. A calculation of the diffraction pattern according to these assumptions has not provided any additional information.

To specify the domain arrangement more accurately, it is now valuable to measure the pole 
figures of the crystal in phase III. Moreover, as the transition presents the characteristic features of a martensitic transformation, the perfect knowledge of the domain arrangement could be helpful to determine the habit plane between phases II and III.

\section{Conclusion.}

It results from this study that $\mathrm{RbAlF}_{4}$ and $\mathrm{KAlF}_{4}$ do not exhibit the same pretransitionnal effects in the vicinity of their respective phase II $\rightarrow$ phase III transitions. Two essential differences arise from the mono-Laue patterns :

- The first one concerns the anisotropy of the diffuse scattering along the MX line of the first Brillouin zone.

In $\mathrm{RbAlF}_{4}$, the diffuse scattering is concentrated around the $\mathrm{X}$ point and roughly extends to half the length of the $M X$ line. The intensity of the $X$ point increases when the temperature is lowered towards $T_{\mathrm{c}_{2}}$ and the DS persists at least $30 \mathrm{~K}$ below $T_{\mathrm{c}_{2}}$. This shows that the correlation length increases along the MX direction when $T_{\mathrm{c}_{2}}$ is approached from above, as expected from the soft mode picture.

In $\mathrm{KAlF}_{4}$ the diffuse scattering is, on the contrary, extended in diffuse rods between the $\mathrm{X}$ and $M$ points. However in this case, it has not been possible to detect whether the shear transformation was preceded by the condensation of the diffuse scattering at a specific point of the MX line when $T_{\mathrm{c}}$ is approached from above.

These two behaviours reveal that the correlations of atomic displacements responsible for the diffuse scattering are not the same in $\mathrm{KAlF}_{4}$ and $\mathrm{RbAlF}_{4}$ when approaching $T_{\mathrm{c}}$. They are clearly $2 \mathrm{~d}$ in $\mathrm{KAlF}_{4}$ whereas this $2 \mathrm{~d}$ character is less pronounced in $\mathrm{RbAlF}_{4}$.

- The second difference comes from the presenoe in the $\mathrm{KAlF}_{4}$ pattern of extra-spots which have never been observed in the case of $\mathrm{RbAlF}_{4}$. These very weak extra-spots are probably connected with phase III of $\mathrm{KAlF}_{4}$ since in this phase they become the most intense Bragg spots of the pattern. This explains why they are not visible in the $\mathrm{RbAlF}_{4}$ pattern since the two compounds do not undergo the same structural rearrangement at the phase II $\rightarrow$ phase III transition. However the presence of these nearly temperature-independent extra-spots may not be considered as an intrinsic feature since it seems to be sample related; nevertheless it must be pointed out that extra-spots are visible in most $\mathrm{KAlF}_{4}$ crystals.

Moreover the knowledge of the domain arrangement in the low temperature phase will now be very useful to interpret the origin of extra-spots. The mapping out and the interpretation of all the extraspots is presently in progress.

As mentioned by Kassan-Ogly and Naish in a recent paper [14], only a few experimental results obtained with the X-ray mono-Laue technique are presently available. In this paper, we have shown that this technique allows at once the mapping out of diffuse scattering and weak extra-spots but also is a powerful tool to investigate a multi-domains structure.

\section{Acknowledgments.}

The authors are indebted to M. Lambert, F. Denoyer and R. Almairac for initial helpful discussions in the design of the diffuse scattering device. They wish to thank J. L. Fourquet for kindly providing the Buerger precession photograph. They are grateful to G. Ripault for the diffuse scattering set-up and to G. Niesseron for the crystal growth. All the calculations were performed with the C.I.R.C.E. facilities.

References

[1] Brosset, C., Z. Anorg. Allgem. Chem. 235 (1987) 139.

[2] Fourquet, J. L., Plet, F., Courbion, G., Bulou, A. and DE PAPE, R., Rev. Chim. Miner. 16 (1979) 490.

[3] Bulou, A., Nouet, J., Kleemann, W., Schafer, F. J. and HEWAT, A.'W., Ferroelectrics 36 (1981) 407.

[4] Bulou, A. and Nọuet, J., J. Phys. C : Solid State Phys. 15 (1982) 183.

[5] Nouet, J., Pannetier, J. and Fourquet, J. L., Acta Crystallogr. B 37 (1981) 32.

[6] Bulou, A., Thesis 1985, Le Mans.

[7] Launay, J. M. Bulou, A., Hewat, A. W., Gibaud A., Laval, J. Y. and Nouet, J., $J$. Physique 46 (1985) 771.
[8] Gibaud, A., Le Bail, A. and Bulou, A., J. Phys. C: Solid State Phys. 19 (1986) 4623.

[9] Bulou, A., Launay, J. M., Rousseau, M., Ridou, C. and Nouet, J., Ferroelectrics 54 (1984) 249.

[10] Bulou, A., Rousseau, M. and Nouet, J., Loyzance, P. L., Mokhlisse, R. and Couzi, M., J. Phys. C : Solid State Phys. 16 (1983) 4527.

[11] SatiJa, S. K., Shapiro, S. M., Salamon, M. B. and Wayman, C. M., Phys. Rev. B 29 (1984) 6031.

[12] Shapiro, S. M., NodA, Y., FUjII, Y. and Yamada, Y., Phys. Rev. B 30 (1984) 4314.

[13] Salamon, M. B., Meilche, M. E. and Wayman, C. M., Phys. Rev. B 31 (1985) 7306.

[14] Kassan-Ogly, F. A. and Naish, V. E., Acta Cryst. B 42 (1986) 297. 